\title{
Validity and reliability of the Turkish version of the Birth Experiences Questionnaire
}

\author{
'Fadime BAYRI BINGÖL \\ (D) ${ }^{1}$ Meltem DEMIRGÖZ BAL \\ (D) ${ }^{2}$ Melike Dişsiz \\ (D) ${ }^{3}$ Sümeyye TOKAT \\ (D) ${ }^{3}$ Melek IŞIK
}

${ }^{1}$ Department of Midwifery, Marmara University Faculty of Health Sciences, İstanbul, Turkey

${ }^{2}$ Health Sciences University Hamidiye Nursing Faculty, İstanbul, Turkey

${ }^{3}$ Esenler Gynecology and Pediatrics Hospital, İstanbul, Turkey

\begin{abstract}
Objective: The aim of this study was to examine the validity and reliability of the Turkish version of the Birth Experiences Questionnaire.

Material and Methods: This methodological study was carried out with 110 couple who were admitted to a in Istanbul between January and December 2019. This research is a methodological study. This study was conducted with 110 couple who gave birth in a public hospital in Istanbul between January and December 2019. The data of the study were obtained using Personal Information Form and Turkish version of Birth Experiences Questionnaire. Birth Experiences Questionnaire measurements were tested with validity and reliability analyzes. For this purpose, validity analysis of data; scope validity index, exploratory factor analysis, confirmatory factor analysis (CFA), reliability analysis; Pearson moment product correlation and Cronbach Alpha reliability coefficient tests were used. In the evaluation of data, t-test, correlation analysis, Cronbach a analysis, and CFA were used.
\end{abstract}

Results: It is a 10-item self-rating scale. To assess the consistency of the questionnaire overtime, test-retest measurement was performed with an interval of 1 day. As a result, no difference was found between the mean scores ( $p>0.05)$. In the analysis conducted for the internal consistency in the reliability study of the Birth Experiences Questionnaire, the Cronbach alpha reliability coefficient all scales was determined for all scales as $\propto=0.78$ for mothers and $\propto=0.86$ for fathers.

Conclusion: In this study, it was shown that the Turkish version of the scale was valid and reliable.

Keywords: Birth experiences, childbirth, reliability, validity.

Cite this article as: Bayrı Bingöl F, Demirgöz Bal M, Dişsiz M, Tokat S, Işık M. Validity and reliability of the Turkish version of the Birth Experiences Questionnaire. Zeynep Kamil Med J 2021;52(1):21-26. 


\section{INTRODUCTION}

Even though thousands of births have occurred around the world daily, majority of people define the birth as the hardest and the most significant experiences of their lifespan in birth psychology studies. ${ }^{[1,2]}$ During that period, due to mental health issues experienced by the parents, negative impacts might occur on emotional commitment with the baby as well as ruining family relations that lead to emotional, cognitive, and behavioral problems in the children in long-term period..$^{[1,3-5]}$ Negative birth perception was reported to trigger psychiatric diseases. ${ }^{[6,7]}$ It is rather crucial for couples to assess their birth experiences as positive since the birth is a factor increasing psychological vulnerability and sustain their psychological wellness.

Positive birth experience is defined as the occurrence of the birth with certain outcomes targeting healthy mother/baby and satisfaction of individual needs. ${ }^{[8]}$ Since a positive birth experience lets parents get stronger, self-realization, self-esteem, and enhancing connection with their babies, it eases the adaptation to role of parenting. A negative birth experience, on the other hand, is defined as an experience including unfulfilled expectations, feeling of failure, and disappointment. ${ }^{[2,4,9]}$

Although negative birth experiences effecting mental health at postpartum period are investigated with mothers, fathers also are reported to experience psychological problems at postpartum period. [10,11] Positive birth experience of fathers might contribute their participation to the family at postpartum period. For instance, the fathers considering the birth experience risky or frightening or feeling not providing sufficient support during the birth period are reported to experience certain problems in the adaptation of the role of becoming father. ${ }^{[12]}$

It is rather important to assess birth experience to gain awareness about mental health of the couples, establish early diagnosis by the physician, prevent serious mental diseases in the future, and determine the infrastructure of the treatment when needed. Even though a number of studies exist in our country investigating mother satisfaction at postpartum period ${ }^{[13]}$ and birth experience, ${ }^{[5,7,14,15]}$ not any studies occurred to examine the birth experience including the fathers in their samples and the assessments with mothers were conducted with instruments including more questions. In studies assessing the psychosocial dimensions of birth experience, the measurement instrument should be brief, clear, standardized, and reliable. The current study might be predicted to close a significant gap in our country. The current study was conducted to present Turkish version of the Birth Experiences Questionnaire developed by Saxbe et al. ${ }^{[1]}$ (2018) including 9 items to assess birth experiences.

\section{MATERIAL AND METHODS}

The present methodological study was carried out in a maternity and children's hospital Istanbul province with primipara women admitting to the hospital to deliver birth and their spouses between the dates January 2019 and December 2019. Those women and their spouses selected through improbable random sampling method, understanding and communicating in Turkish, not having any physical and psychological problems to participate in the study, and being volunteer were included in the study. Those women diagnosed as risky pregnancy, developing any medical complication in the mother or baby, and taking cesarean delivery were excluded from the study. The data were collected through face-to-face interviews. The sample size was planned as 10 times more than items ${ }^{[16,17]}$ so that the study was completed with 110 couples. Test-retest measurement was completed in one day intervals with 40 couples to assess stability of the questionnaire overtime. The permission was obtained from Ethic Committee of Health Sciences Faculty of Marmara University (10.09.2018-179). Moreover, the couples included in the study were explained the aim, method, and their contributions to get their verbal permission and they were also informed about they could withdraw from the study whenever they wished.

The data were collected using information form and the Birth Experiences Questionnaire.

\section{Introductory Information Form}

It consisted of items including week of the pregnancy, any health problems during pregnancy and delivery method, as well as age, education, and occupation of the participants.

\section{The Birth Experiences Questionnaire}

The questionnaire developed by Saxbe et al. ${ }^{[1]}(2018)$ is used in the assessment of birth experience. The permission was obtained from Saxbe for the Turkish validity and reliability study of the questionnaire. It is a 20 itemed self-assessment questionnaire; 10 items for mother and 10 items for spouses. It was developed specifically for birth experience and scanning purposes and assesses the psychological dimension of the birth. The original questionnaire was developed with newly delivered mothers and spouses and confirmed accordingly. Cronbach's alpha value for original questionnaire was 0.81 for mothers and 0.80 for fathers. It includes the items related with birth experience. It assesses the stress, fear, and worries of couples during the period of pregnancy. The Birth Experiences Questionnaire is the shortest, simplest, and the most practical one among the current scales. It is rather suitable for the primary assessment of the birth both for mothers and fathers. It is recommended to implement the questionnaire in the hospital just 1 or 2 days after the birth. ${ }^{[1]}$ Higher scores mean negative birth experience.

Data were analyzed using SPSS version 21 (SPSS Inc., Chicago, IL, USA) and SPSS Amos (Analysis of Moment Structures) version 23. Test-retest methodology was used to assess the consistency overtime, and Pearson's correlation coefficient was calculated. For evaluating the internal consistency and item-total correlation coefficients, Pearson's moment correlation coefficient was used. Cronbach's alpha reliability coefficient was performed to find the coefficient of internal consistency. The Lawshe technique was used to examine the opinions of experts on content validity. Further, an exploratory factory analysis and a confirmatory factor analysis (CFA) were used to assess construct validity.

\section{Findings}

The mean age of the mothers in the study was $23.28 \pm 6.36$ (min: 19 and max: 31) and fathers' $26.54 \pm 2.89$ ( $\min : 21$ and max: 38); mothers had educated $8.30 \pm 1.38$ ( $\min : 8$ and max: 16) years and fathers $8.51 \pm 1.63$ (min: 8 and max: 16) years. The majority of the mothers 
Table 1: Item-subdimension total score correlations of subdimensions of the Birth Experiences Questionnaire

\begin{tabular}{|c|c|c|c|c|c|}
\hline \multirow[t]{2}{*}{ Subdimensions and items } & \multicolumn{2}{|c|}{$\begin{array}{l}\text { Item-subdimension total } \\
\text { score correlation coefficient }\end{array}$} & \multicolumn{2}{|c|}{$\begin{array}{l}\text { Item-total correlation } \\
\text { coefficient }\end{array}$} & \multirow{2}{*}{$\frac{\text { Cronbach alpha }}{\propto}$} \\
\hline & $\mathbf{r}$ & $\mathbf{p}$ & $\mathbf{r}$ & $\mathbf{p}$ & \\
\hline \multicolumn{6}{|l|}{ Mother $(n=110)$} \\
\hline \multicolumn{6}{|l|}{ Stress } \\
\hline Item 1 & 0.88 & 0.000 & 0.42 & 0.000 & \\
\hline Item 2 & 0.85 & 0.000 & 0.33 & 0.000 & \\
\hline Item 3 & 0.73 & 0.000 & 0.44 & 0.000 & 0.87 \\
\hline Item 4 & 0.73 & 0.000 & 0.44 & 0.000 & \\
\hline Item 5 & 0.73 & 0.000 & 0.44 & 0.000 & \\
\hline \multicolumn{6}{|l|}{ Fear } \\
\hline Item 6 & 0.94 & 0.000 & 0.50 & 0.000 & 0.89 \\
\hline Item 7 & 0.95 & 0.000 & 0.47 & 0.000 & \\
\hline \multicolumn{6}{|l|}{ Support } \\
\hline Item 8 & 0.92 & 0.000 & 0.52 & 0.000 & 0.84 \\
\hline Item 9 & 0.93 & 0.000 & 0.39 & 0.000 & \\
\hline \multicolumn{6}{|l|}{ Father $(n=110)$} \\
\hline \multicolumn{6}{|l|}{ Stress } \\
\hline Item 1 & 0.77 & 0.000 & 0.51 & 0.000 & \\
\hline Item 2 & 0.71 & 0.000 & 0.38 & 0.000 & \\
\hline Item 3 & 0.60 & 0.000 & 0.74 & 0.000 & 0.80 \\
\hline Item 4 & 0.83 & 0.000 & 0.53 & 0.000 & \\
\hline Item 5 & 0.78 & 0.000 & 0.49 & 0.000 & \\
\hline \multicolumn{6}{|l|}{ Fear } \\
\hline Item 6 & 0.95 & 0.000 & 0.52 & 0.000 & 0.89 \\
\hline Item 7 & 0.95 & 0.000 & 0.60 & 0.000 & \\
\hline \multicolumn{6}{|l|}{ Support } \\
\hline Item 8 & 0.94 & 0.000 & 0.72 & 0.000 & 0.87 \\
\hline Item 9 & 0.94 & 0.000 & 0.75 & 0.000 & \\
\hline
\end{tabular}

$(98.2 \%)$ were determined to be housewife and fathers were workers (97.3\%). The mean gestational week of the participants is $38.21 \pm 0.83$ (min: 36 and max: 41 ). About $80.9 \%$ of the participants reported not experienced any problems in their pregnancy and $94.5 \%$ of them stated that they delivered birth through normal spontaneous vaginal labor.

\section{Linguistic Equivalence, Content Validity Analysis}

To evaluate the content validity of the instrument, the original version of the Birth Experiences Questionnaire was translated into Turkish version by a psychiatric nurse and lecturer, a obstetrics and gynecology nurse and lecturer, and an English instructor. The researchers reviewed the translated scale and collaborated in generating a Turkish form of text. A Turkish teacher then evaluated the text for linguistic suitability and comprehensiveness. In the next stage, the Turkish version of the scale was blindly translated back into En- glish by two individuals, namely, a lecturer who had completed the doctorate study and lived abroad, and an individual who was studying and living abroad. The scale was then retranslated into Turkish by a lecturer. By this version, it was checked out whether it had changed the meaning of the original scale or not. Then, the final form of the scale was obtained.

\section{Content Analysis}

After the linguistic equivalence of the scale was tested, the Turkish version was submitted to 11 experts for the analysis of content validity. The experts were asked to score each item on a scale between 1 and 5 (1 point: Inappropriate; 2 points: Slightly appropriate; 3 points: I'm undecided; 4 points: Appropriate; and 5 points: Very appropriate). The differences in experts' opinions were examined using the Lawshe technique, and the data obtained from the experts were an- 


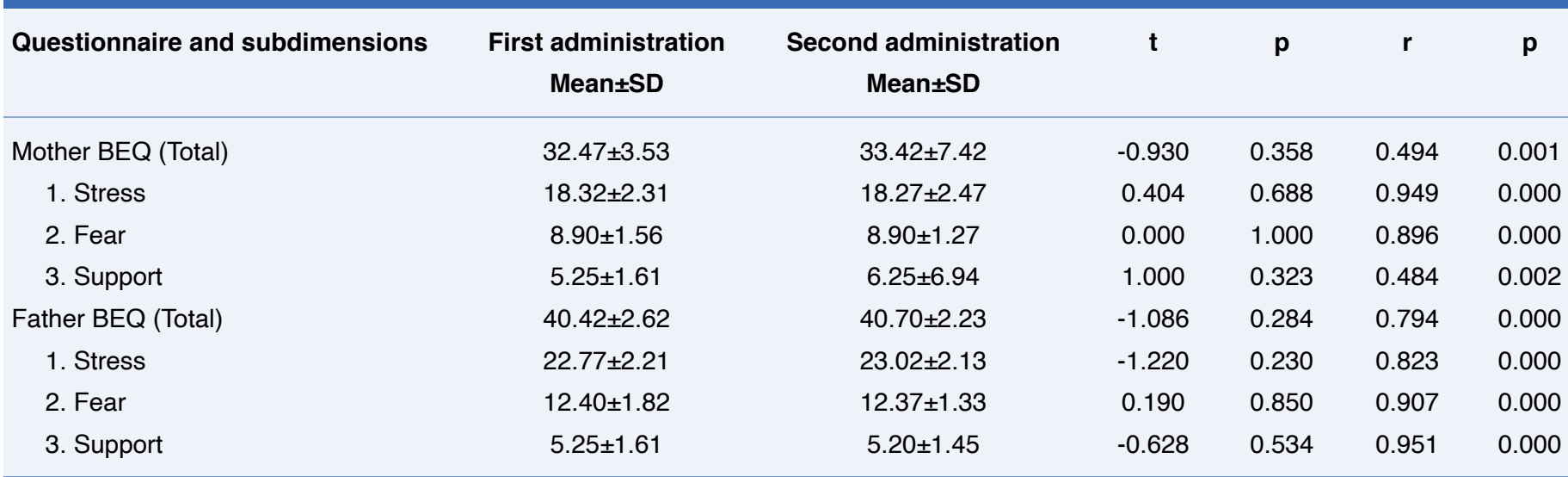

SD: Standard deviation; BEQ: Birth Experiences Questionnaire; t: Paired samples t-test; r: Pearson correlation test.

alyzed using the content validity index (CVI). Ultimately, the CVI for the items was found to be $92 \%$. Once the evaluations of the experts were obtained, the agreed on final scale was administered to 20 participants outside of this sample in a pilot study.

\section{Item Analysis}

When total score correlations of the 18 items were examined for the reliability testing of the Birth Experiences Questionnaire, the reliability coefficient was found to vary between 0.33 and 0.52 for mothers and 0.38 and 0.75 for fathers. It was found that there was a positive and statistically significant correlation between the item scores and the overall scale score $(p<0.000)$ (Table 1$)$. It was shown by investigating the item-subscale total score correlations of each subscale of the Birth Experiences Questionnaire that the reliability coefficients (Pearson's correlation) for the 5 items in the "stress" subscale for mothers were in the range of $r=0.33-0.44$ and it was $r=0.38-0.74$ for fathers. Meanwhile, for the 2 items in the "Fear" subscale, the reliability coefficients ranged from $r=0.47$ to 0.50 for mothers and $r=0.52$ to 0.60 for fathers. Further, the reliability coefficients for the 2 items in the "Support" subscale were between $r=0.39$ and 0.52 for mothers and $r=0.72$ and 0.75 for fathers. This shows that the correlation coefficients of all items have positive and statistically significant correlations $(p<0.001)$ (Table 1). As in the original scale, item analysis was not performed for $10^{\text {th }}$ item.

\section{The Internal Consistency Reliability Coefficient}

As a result of the reliability studies of Birth Experiences Questionnaire, Cronbach's alpha internal consistency coefficient of the questionnaire was found $\propto=0.78$ for mothers and $\propto=0.86$ for fathers in overall questionnaire.

\section{Test and Retest}

For testing the consistency overtime of the Turkish version of the Birth Experiences Questionnaire, 110 women with their spouses got the first evaluation after $2 \mathrm{~h}$ of the delivery and they reinvited to the post-maternity clinic after $24 \mathrm{~h}$ to get a second respond. Couples were interviewed separately. To avoid a possible bias, couples were interviewed by different health-care professionals they never met before. Test-retest measurements performed in 1 day intervals were assessed through Pearson product-moment correlation coefficient and t-test. When the correlation between the scores of the first and second administration of the Birth Experiences Questionnaire was examined using Pearson's correlation analyses, it was found that the reliability coefficients for the difference between the two measurements of the scale ranged between 0.48 and 0.95 . This demonstrates a positive, strong, statistically significant correlation $(p<0.001)$ (Table 2). When the mean scores of the participants at the two different time periods were compared using the dependent groups t-test, a statistically significant difference was not found between the mean scores ( $p>0.05)$ (Table 2).

\section{Construct validity}

Three-dimensional CFA was performed for mothers and fathers to ensure construct validity. As the result of CFA for mothers, fit indices were as follows: Chi-square $=17.492(p=0.000)$, degree of freedom=24 $\left(X^{2}=17.492 ; d f=24, X^{2} / d f=0.729\right)$, root-mean-square error of approximation $(\mathrm{RMSEA})=0.071 \quad(\mathrm{p}<0.05)$, standardized root-meansquare residual (SRMR $=0.036$, comparative fit index $[\mathrm{CFI}]=0.98$, non-normed fit index $(\mathrm{NNFI})=0.69$, goodness-of-fit index $[\mathrm{GFI}]=0.96$, and adjusted goodness-of-fit index $(A G F I)=0.93$. The factor loads for all items were found to 0.69 in the CFA. The diagram for the CFA is shown in Figure 1. As in the scale developed by Saxbe et al., ${ }^{[1]} 10^{\text {th }}$ item was not subjected CFA.

As the result of three-dimensional CFA for fathers, fit indices were as follows: Chi-square $=27.078(p=0.000)$, degree of free$\operatorname{dom}=24\left(X^{2}=27.078 ; d f=24 . X^{2} / d f=1.12\right), R M S E A=0.034(p<0.05)$, $\mathrm{SRMR}=0.050, \mathrm{CFI}=0.91, \mathrm{NNFI}=0.62, \mathrm{GFI}=0.94$, and $\mathrm{AGFI}=0.90$. The factor loads for all items were found to 0.61 in the CFA. The diagram for the CFA is shown in Figure 2.

The mean Birth Experiences Questionnaire scores of mothers included in the study were found $34.25 \pm 2.68$ ( $\min : 31$, max: 42) and mean scores of fathers were determined as $40.20 \pm 4.18$ (min: 35, max: 50). 


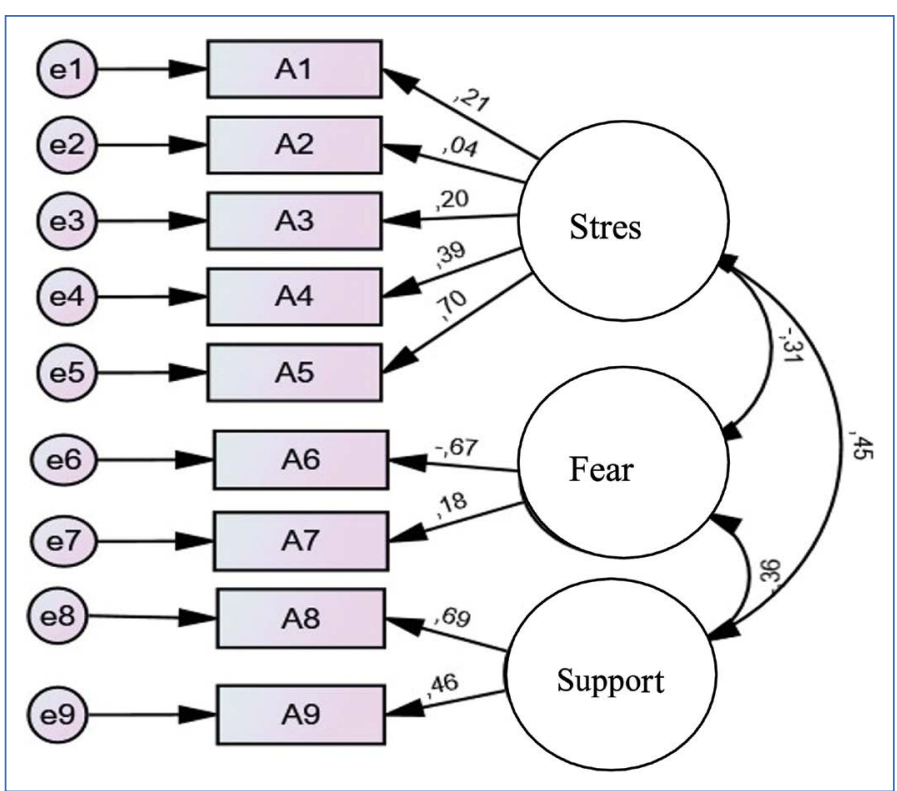

Figure 1: BEQ two-factor confirmatory factor analysis diagram.

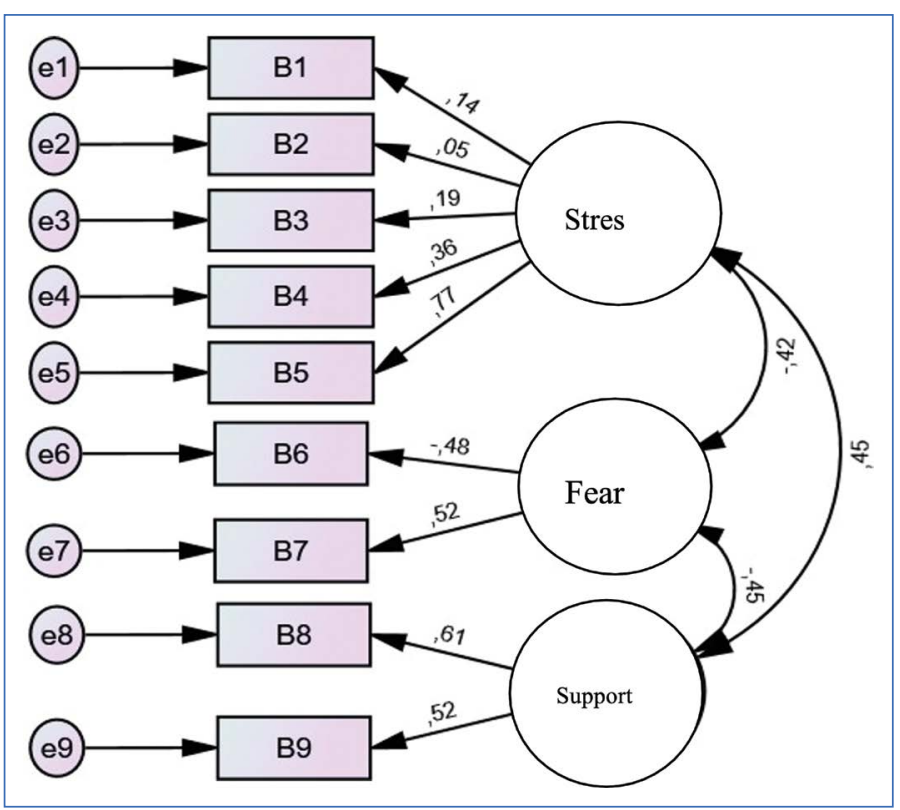

Figure 2: BEQ four-factor confirmatory factor analysis diagram.

\section{DISCUSSION}

At present study, validity and reliability study of the Birth Experiences Questionnaire was realized and the results indicated that Turkish version of the Birth Experiences Questionnaire had appropriate psychometric characteristics. As for the reliability analysis of the Birth Experiences Questionnaire test-retest, internal consistency and item analysis were utilized. Test-retest reliability is the degree to which test scores remain unchanged when measuring a stable individual characteristic on different occasions. Having statistically significant level of relation in test-retest measurement supported the reliability of scores obtained from the Birth Experiences Questionnaire with regard to stability overtime. ${ }^{[16-19]}$ Another supportive finding about the reliability of the questionnaire was that it had statistically significant level of internal consistency coefficient. Cronbach alpha techniques were used to evaluate internal consistency of the questionnaire since it was suitable for Likert-type scales. A high coefficient alpha means a high degree of internal consistency that is each of items in the scale is consistent with one another and the scale consists of items that predict the elements of the same characteristics. Alpha coefficient is used to determine reliability by comparing the amount of shared variance, or covariance, among the items making up an instrument to the amount of overall variance and presented with values between 0 and $1{ }^{[16,19]}$ In reliability study of Turkish version of the Birth Experiences Questionnaire, it was identified that Cronbach alpha reliability coefficient reached the desired level for each of the three dimensions.

If the items in a scale had equal weights and were in the form of separate units, correlation coefficient expected to be higher. Higher correlation coefficient means higher level of relation between the item and characteristic it aims to measure. Even though a standard does not exist in terms of item total score correlation's decrease the certain level, it is recommended that correlations not being negative and over 0.25 or 0.30 . Higher correlation coefficient means higher reliability for the items in the scale. ${ }^{[16,19]}$ When the item-total score correlations for each of the subscales regarding the reliability study of the Birth Experiences Questionnaire were examined, all the subscales were observed to meet required criteria.

The experts reviewed the items in terms of content validity and agreed on the fact that the scale demonstrated a good content validity in its original form. The high degree of experts conformity is an important finding for verifying the content validity of the Turkish version of the Birth Experiences Questionnaire.

CFA was performed for each of the subdimensions to confirm construct validity in Turkish version adaptation of the questionnaire. The most commonly employed fit tests are the Chi-square, RMSEA, SRMR, CFI, NNFI, GFI, and AGFI. ${ }^{[16,18]}$ The fit statistics resulting from a CFA must be at the desired levels. For a model to be acceptable, the Chi-square value is expected to be non-significant. In this study, the Chi-square value was found to be non-significant across all dimensions. This suggested a good model fit.

RMSEA value $\leq 0.08$ with $p<0.05$ (statistical significance) indicates a good model fit, while a value $\leq 0.10$ is a poor model fit. In this study, RMSEA was found to be significant in each dimension, indicating a good fit. Factor loads should not be $<0.30$. The following values represent a good fit model: SRMR values of $<0.10$; CFI, GFI, and NNFI values equal to or greater than 0.90 ; and AGFI values $\geq 0.80$. [16-19] In the statistical analysis, it was found that the Turkish version of the Birth Experiences Questionnaire satisfied all of fit criteria.

\section{Research Limitations}

The data based on self-reporting are an important limitation in this research. Since the data collected to assess birth experience based on self-reporting, a certain degree of fallibility should be taken into consideration. The function of the questionnaire that directs participants to birth psychotherapist or psychiatry clinics just by regarding the scores they obtained should be paid attention. Moreover, the couples' not admitting to the hospital being excluded from the study are another important limitation. The present study cannot be gene 
ralized to all the women in postpartum period since it was conducted only with women admitting to maternity and children's hospital in the province of Istanbul.

\section{CONCLUSION}

In this study, it has been investigated the validity and reliability of the Turkish version of the Birth Experiences Questionnaire. It is recommended that the Turkish version of the Birth Experiences Questionnaire can be used as a tool to determine negative birth experiences of women together with their spouses. The questionnaire may also provide guidance to health-care professionals and be effective for identifying negative birth experiences of couples at postpartum period as well as early detection of psychological symptoms to direct them psychotherapists, psychiatrists, and other health-care professionals when needed.

\section{Special Thanks}

To experts and couples participated in the study.

\section{Statement}

Ethics Committee Approval: The Marmara University Institute of Health Sciences Ethics Committee granted approval for this study (date: 10.09.2018, number: 179).

Informed Consent: Verbal informed consent was obtained from patients who participated in this study.

Peer-review: Externally peer-reviewed.

Author Contributions: Concept - FBB, MDB; Design - FBB, MD; Supervision - MDB; Resource - FBB; Materials - FBB; Data Collection and/or Processing - ST, MI; Analysis and/or Interpretation - MD; Literature Search FBB, MD; Writing - FBB, MD; Critical Reviews - MDB.

Conflict of Interest: The authors have no conflict of interest to declare.

Financial Disclosure: The authors declared that this study has received no financial support.

\section{REFERENCES}

1. Saxbe D, Horton KT, Tsai AB. The birth experiences questionnaire: $A$ brief measure assessing psychosocial dimensions of childbirth. J Fam Psychol 2018;32(2):262-8.

2. Weeks F, Pantoja L, Ortiz J, Foster J, Cavada G, Binfa L. Labor and birth care satisfaction associated with medical interventions and accompaniment during labor among chilean women. J Midwifery Womens Health 2016;62(2):196-203.

3. Fallon V, Halford JC, Bennett KM, Harrold JA. The postpartum specific anxiety scale: Development and preliminary validation. Arch Womens Ment Health 2016;19(6):1079-90.

4. Ayers S. Birt trauma and post-traumatic stres disorder: The importance of risk and resilience. J Reprod Infant Psychol 2017;35(5):427-30.
5. Yalnız H, Canan F, Genç RE, Kuloğlu, MM, Geçici, Ö. Development of a scale of Traumatic Childbirth Perception. Turk Med J 2016;8(3):81-8.

6. Meltzer-Brody S, Maegbaek ML, Medland SE, Miller WC, Sullivan P, Munk-Olsen T. Obstetrical, pregnancy and socio-economic predictors for new-onset severe postpartum psychiatric disorders in primiparous women. Psychol Med 2017;47(8):1427-41.

7. Bingöl FB, Bal MD. The risk factors for postpartum posttraumatic stres disorder and depression. Perspect Psychiatr Care 2020;56(4):851-7.

8. Gözükara F, Eroğlu K. Factors that effect the choices of primipars on the mode of delivery. Hacettepe University Faculty of Health Sciences Nursing Journal 2008;15(1):32-46.

9. Edhborg M, Seimyr L, Lundh W, Witstrom AM. Fussy child-difficult parenthood? comparisons between families with a "depressed" mother and non-depressed mother 2 Month postpartum. J Reprod Infant Psychol 2000;18(3):225-38.

10. Cameron EE, Sedov ID, Tomfohr-Madsen LM. Prevalence of paternal depression in pregnancy and the postpartum: An updated meta-analysis. J Affect Disord 2016:206:189-203.

11. Koch S, De Pascalis L, Vivian F, Renner AM, Murray L, Arteche A. Effects of male postpartum depression on father-infant interaction: The mediating role of face processing. Infant Ment Health 2019;40(2):26376.

12. Ferguson S, Davis D, Browne J. Does antenatal education affect labour and birth? A structured review of the literature. Women Birth 2013;26(1):5-8.

13. Güngör İ, Beji NK. Development and psychometric testing of the scales for measuring maternal satisfaction in normal and caesarean birth. Midwifery 2012;28(3):348-57.

14. Kızılkaya S. Sezaryen ya da Normal Spontan Doğum Yapan Primiparlarda Doğum Deneyiminin Doğum Sonu Yaşam Kalitesine Etkisi. Marmara University, Institute of Health Sciences, Master Thesis, 2013, Istanbul. [in Turkish].

15. Korukcu HÖ, Kukulu K, Fırat MZ. The reliability and validity of the Turkish version of the wijma delivery expectancy/experience questionnaire (W-DEQ) with pregnant women. J Psychiatr Ment Health Nurs 2012;19(3):193-202.

16. Esin, M. N. (2014). Data collection methods and tools, \& reliability and validity of data collection tools. In S. Erdogan, N. Nahcivan, \& M. N. Esin (Eds.), Research in nursing (pp. 100-120). Istanbul: Nobel Medical Bookstores. [in Turkish].

17. Gozum, S., \& Aksayan, S. (2002). Guidelines for intercultural scale adaptation II: Psychometric properties and cross-cultural comparison. Journal of Research and Development in Nursing, HEMAR-GE, 4(2), 9-20. [in Turkish].

18. Erefe I, editors. 2004. Nature of data collection tools. In: Research principles, processes and methods in nursing. Nursing research and development association publications. Ankara: Odak Ofset. [in Turkish].

19. Oner N. 2006. Psychological testing of samples used in Turkey: a reference source. Extended $2^{\text {nd }}$ Edition. Istanbul: Bogazic,i University Printing House. [in Turkish]. 